\title{
Distribution Network Reliability Assessment Based on User Response Xi Chen
}

School of electrical engineering, North China Electric Power University, Baoding 071000, China. slz4chenxi@163.com

Keywords: demand response; TOU price; price elasticity coefficient; load curve construction; curve clustering; reliability evaluation

\begin{abstract}
Demand response can guide the demand side changing power mode, to achieve the purpose of peak load shifting, and load curve changes will inevitably affect the system's reliability. Taking the TOU price as an example, we discuss quantitatively the effects of demand response on power supply reliability of distribution network. Firstly, with the price elasticity coefficient in economics, contact is established between the load curve and price. Secondly, considering the different industry, the load curve were evaluated respectively after the implementation of TOU price. Thirdly, obtain the total load curve. Finally, using curve clustering method to analyze the load curve. Combined with the examples show that the demand response can effectively improve the phenomenon of peak valley load curve, and improve the reliability of distribution network.
\end{abstract}

\section{Introduction}

The distribution system is directly based on the user's part of power system. Its influence on power quality and reliability is also the most direct. According to statistics, there are about80\% power outages due to fault of distribution system [1]. However, with the development of power industry from the traditional monopoly to power market competition mechanism, distribution network planning becomes more and more commercialized, and the profits will become the focus of all investment and operating decisions. Include the reliability index in the profit decision, to achieve the balance of investment and the appropriate level of reliability.

\section{The user load characteristics of TOU price}

\section{The coefficient of elasticity of demand for users}

According to the principle of economics, the elastic coefficient of electric load said the percentage of changes in demand for electricity caused by electricity price changes in a certain period, the general formula can be expressed as

$$
E=\frac{\Delta d}{\Delta \rho} \frac{\rho_{0}}{d_{0}}
$$

In formula1, $E$ as the demand elasticity coefficient of electricity; $\Delta \rho$ for the changes in electricity prices; $\Delta d$ said the change of electrical demand based on price changing; $\rho_{0}$ and $d_{0}$ are electricity price and electricity demand respectively

\section{Model for multi period load reduction and transfer}

In the literature [2], the load is divided into the following two categories:

1. The load cannot transfer to other time interval

2. The load can transfer to other time interval

For the second class of load, the elasticity between load in i time and price in $\mathrm{j}$ time for the same user can be defined as

$$
E_{L}(i, j)=\frac{d_{L}(i)-d_{L 0}(i)}{\rho(j) \rho_{0}(j)} \frac{\rho_{0}(j)}{d_{L 0}(i)}
$$

In 24 hours a day for a cycle, $\lambda_{L}(i)$ said the power change rate of user $L$ at stage i since the implementation of TOU price. 


$$
\lambda_{L}(i)=\frac{d_{L}(i)-d_{L 0}(i)}{d_{L 0}(i)}=\sum_{j=1}^{24}\left\{E_{L}(i, j) \frac{\left[\rho(j)-\rho_{0}(j)\right]}{\rho_{0}(j)}\right\}
$$

If use the usual price to express price before the implementation of TOU price $\rho_{0}(j), k(j)=\frac{\left[\rho(j)-\rho_{0}(j)\right]}{\rho_{0}(j)}$ is for the peak and valley price floating ratio, to show the floating part on the price of the usual period compared with the peak and valley price. In consideration of its peak load and peak load shifting effect, the formula can be rewritten as

$$
\lambda_{L}(i)=\sum_{j=1, j \neq i}^{24} E_{L}(i, j) k(j)+E_{L}(i) k(i)
$$

For the second kinds of load, considering the self-elasticity load and cross elasticity of the load, the calculation formula for the ratio of the load reduction and transfer in any time is

$$
\left\{\begin{array}{c}
\lambda_{f f}=k_{f} E_{L}(i), \forall i \in T_{f} \\
\lambda_{p p}=0, \forall i \in T_{p} \\
\lambda_{g g}=k_{g} E_{L}(i), \forall i \in T_{g} \\
\lambda_{f p}=k_{f} E_{L}(i, j), \forall i \in T_{f}, \forall j \in T_{p} \\
\lambda_{f g}=\left(k_{f}-k_{g}\right) E_{L}(i, j), \forall i \in T_{f}, \forall j \in T_{g} \\
\lambda_{p g}=-k_{g} E_{L}(i, j), \forall i \in T_{p}, \forall j \in T_{g}
\end{array}\right.
$$

In formula5, $T_{f} 、 T_{p} 、 T_{g}$ are peak, flat and valley period of division respectively. $i$ is for any period.

\section{Load demand response matrix}

When the power sector get user's load response characteristics, they can analyze load curve. [3] Load response model can be described based on TOU price mechanism.

$$
d(i)=\left\{\begin{array}{l}
d_{f}+d_{f} \lambda_{f f}-d_{f} \lambda_{f p}-d_{f} \lambda_{f g}, i \in T_{f} \\
d_{p}+d_{f} \lambda_{f p}+d_{p} \lambda_{p p}-d_{p} \lambda_{p g}, i \in T_{p} \\
d_{g}+d_{f} \lambda_{f g}+d_{p} \lambda_{f g}+d_{g} \lambda_{g g}, i \in T_{g}
\end{array}\right.
$$

In this formula, $d_{f} 、 d_{p} 、 d_{g}$ are average value of the total load in peak usual and valley period in the corresponding period respectively. The type (9) in matrix form, can be described as

\section{Build load curve}

$$
d^{\prime}=d+\lambda \times d
$$

Considering different industry tariff policy and the extent of the response is not the same, in the actual calculation, combined with the actual price policy, load curve are calculated by a model, togethered into total load curve.

Build the load characteristic curve of the whole society can be divided into 4 steps [4]:

(1) Calculate the highest proportion of load in various industries.

(2) Construct industry benchmark year load curve.

(3) Superpose the load curve of the stack above.

(4) Correct the curve (each point load divided by correction coefficient) can simulate the whole society load curve.

Because the average load / maximum load = load rate, while the average load = electricity consumption/electricity time, which is the highest load =electricity consumption/ (electricity time * load rate), to be launched

$\frac{\text { the maximum load in industry }}{\text { total maximum load }}=\frac{\text { the electricity consumption in industry }}{\text { total electricity consumption }} \times \frac{\text { total load rate }}{\text { load rate in industry }}$ The specific calculation formula is as follows:

$$
B_{f}=B_{d} \times L_{q} \div L_{h}
$$

In this formula, $B_{f}$ is the maximum load proportion of the industry. $B_{d}$ is the monthly 
consumption accounted for the whole society. $L_{q}$ is load factor of social load curve. $L_{h}$ is load rate for the industry.

\section{The cluster computing of reliability considering the load curve}

\section{Curve cluster}

This article takes "Minimum geometric distance" rule to cluster the duration load curve.

If the original duration load curve is $\mathrm{y}=\mathrm{f}(\mathrm{x})$, which domain is[a, b], and clustered curve is $\mathrm{y}=\mathrm{g}(\mathrm{x})$. The objective of "Minimum geometric distance" clustering is to satisfy the minimum value of $\mathrm{z}$ in (8).

$$
z=\int_{a}^{b}\left[(f(x)-g(x))^{2}\right]^{\frac{1}{2}}
$$

But if only this rule is taken to cluster the duration load curve, it will make the clustered curve's energy is not consistent with the original duration load curve and the original chronological load curve, which does not meet the conditions of type (9).

$$
\int_{a}^{b} f(x) \mathrm{dx}=\int_{a}^{b} \mathrm{~g}(x) \mathrm{dx}
$$

In summary, if the collection $\mathrm{H}$ of sequence $h_{1}, h_{2}, h_{3} \cdots h_{k}$ said the load value of cluster curve in each interval set, the model in type (10) can represent this cluster rule.

$$
\begin{gathered}
\min z=\int_{a}^{b}\left[(f(x)-\mathrm{g}(x))^{2}\right]^{\frac{1}{2}} \\
\left\{\begin{array}{l}
\int_{a}^{b} f(x) \mathrm{dx}=\int_{a}^{b} g(x) \mathrm{dx} \\
x \in[a, b] \\
g(x) \in \mathrm{H} \\
g(x) \in[0,1]
\end{array}\right.
\end{gathered}
$$

Solution of type (10) is clustering curve $=g(x)$, which should contain the number of clusters, the load value of each clustering curve and duration. The reliability index calculation

Sustained annual load curve can be represented by function $\mathrm{L}=\mathrm{G}(\mathrm{K}, \mathrm{m}(\mathrm{k}), \mathrm{h}(\mathrm{k}))$ after clustering, where $\mathrm{K}$ represents the number of clustering areas, $\mathrm{h}(\mathrm{k})$ represents the load level of $\mathrm{K}^{\text {th }}$ clustering value, $\mathrm{k} \in\{1,2,3, \ldots, \mathrm{K}\}, \mathrm{m}(\mathrm{k})$ represents the persistent time of load level $\mathrm{h}(\mathrm{k}$ ) (the smallest unit is 1 hour)

For the discussion of calculation method and the change rule of the reliability index of distribution network under the load curve, according to the significance and method of calculating, reliability index can be divided into the following 3 categories: frequency index, probability index and power index [5].

\section{Example}

\section{Build load curve}

Table 1 is the main power consumption structure of Nanjing city in 2001, including industry's total electricity consumption accounted for about $95 \%$ of total electricity consumption. The rest such as agriculture, geological survey and exploration industry, transportation, posts and telecommunications, accounting for about $5 \%$, so we need to modify the curves obtained, with each point load divided by the correction coefficient of 0.95 , to simulate load curve of the whole society. 
Table 1 The main power consumption structure of Nanjing city in 2001

\begin{tabular}{|c|cc|} 
& \multicolumn{2}{c}{ Year 2001 } \\
\hline $\begin{array}{c}\text { Social electricity consumption } \\
\text { statistics/Ten thousand kWh }\end{array}$ & 112933 & 140530 \\
\hline 1Heavy industry/\% & 63.3 & 54.1 \\
\hline 2 Light industry/\% & 11.2 & 11.4 \\
\hline 3 Commerce/\% & 4.0 & 6.3 \\
\hline 4 Other business/\% & 6.3 & 9.2 \\
\hline 5 Urban population & 10.1 & 13.9 \\
\hline
\end{tabular}

The highest load of industry and the results of the load components are as follows, build industrial and commercial life load curve data by the data.

Table 2 The results of the load components

\begin{tabular}{|c|c|c|c|c|c|c|}
\hline Date & Classification & $\begin{array}{l}\text { The proportion } \\
\text { of electricity } \%\end{array}$ & $\begin{array}{l}\text { Industr } \\
\text { y load } \\
\text { factor }\end{array}$ & $\begin{array}{l}\text { Society } \\
\text { load } \\
\text { rate }\end{array}$ & $\begin{array}{l}\text { The highest } \\
\text { proportion of } \\
\text { the load/\% }\end{array}$ & $\begin{array}{c}\text { The } \\
\text { highest } \\
\text { load/MW }\end{array}$ \\
\hline \multirow{5}{*}{$\begin{array}{c}2001 \\
\text { April }\end{array}$} & Heavy industry & 63.3 & 0.89 & 0.82 & 58.32 & 1005.34 \\
\hline & Light industry & 11.2 & 0.62 & 0.82 & 14.81 & 255.34 \\
\hline & Commerce & 4.0 & 0.66 & 0.82 & 4.97 & 85.67 \\
\hline & Other business & 6.3 & 0.68 & 0.82 & 7.60 & 130.96 \\
\hline & Resident & 10.1 & 0.53 & 0.82 & 15.63 & 269.37 \\
\hline
\end{tabular}

\section{Considering the impact of TOU price}

\begin{tabular}{|c|c|c|c|c|c|}
\hline \multirow{3}{*}{ Type } & \multicolumn{2}{|l|}{ Table3 } & \multicolumn{2}{|c|}{ Price elasticity } & \\
\hline & \multicolumn{2}{|c|}{$\begin{array}{l}\text { Coefficient of } \\
\text { self-elasticity }\end{array}$} & \multicolumn{3}{|c|}{ Coefficient of cross elasticity $E(i, j)$} \\
\hline & & peak-flat & peak-valley & flat-valley \\
\hline Heavy industry & \multicolumn{2}{|c|}{-0.38} & 0.03 & 0.30 & 0.03 \\
\hline Light industry & \multicolumn{2}{|l|}{-0.20} & 0.02 & 0.08 & 0.02 \\
\hline commerce & \multicolumn{2}{|l|}{-0.12} & 0.02 & 0.02 & 0.02 \\
\hline \multirow[t]{2}{*}{ Resident } & \multicolumn{2}{|l|}{-0.20} & 0.02 & 0.04 & 0.02 \\
\hline & Table4 & \multicolumn{4}{|c|}{ Pricing policy } \\
\hline Type & Time & & e division & & $\begin{array}{l}\text { Price } \\
\text { fluctuation }\end{array}$ \\
\hline \multirow{3}{*}{$\begin{array}{l}\text { Large } \\
\text { industry }\end{array}$} & Peak & 08: & $0-16: 30$ & & up 53\% \\
\hline & Peacetime & 06: & $0-08: 30,1$ & $: 30-21: 00$ & constant \\
\hline & Low & & $0-06: 30$ ne & t day & down $41 \%$ \\
\hline \multirow{3}{*}{ Commerce } & Peak & & $0-19: 00$ & & up 53\% \\
\hline & Peacetime & 06: & $0-09: 00,1$ & $: 00-24: 00$ & constant \\
\hline & Low & & $0-06: 30 \mathrm{n}$ & xt day & down $41 \%$ \\
\hline \multirow{3}{*}{ Resident } & Peak & & $0-01: 00 \mathrm{n}$ & xt day & up $50 \%$ \\
\hline & Peacetime & & $0-03: 30,1$ & $: 30-18: 30$ & constant \\
\hline & low & & $0-10: 30$ & & down 50\% \\
\hline
\end{tabular}

Combined with the data, obtain different industries demand response matrix by type5, again get load after the implementation of TOU price by type7, obtain residents living electricity load curves shown in Figure 1 that do not use time-sharing electricity price and use time-sharing electricity price . The industrial and commercial load curve can be obtained by the same method. 


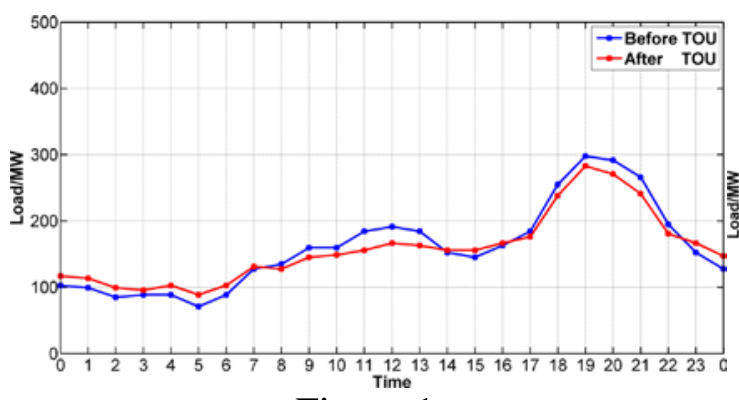

Figure 1

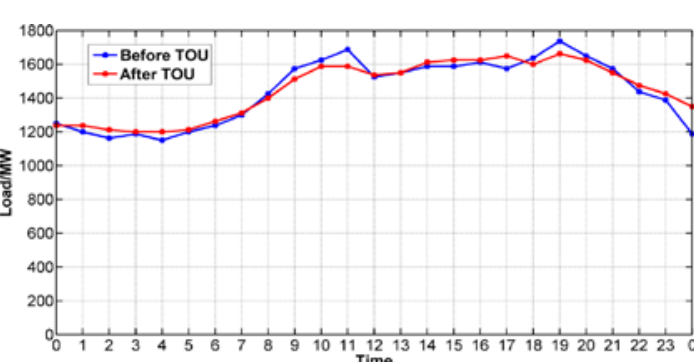

Figure 2

Achieving comprehensive of the load curve above industry, get the total load curve as Figure 2 with correction coefficient. The observation curve can be seen, through the regulation of TOU price, play a certain role in shifting.

\section{Reliability assessment}

Calculate the reliability index based on load curve, and reliability indexes are as follows:

$$
\text { SAIFI SAIDI CAIDI ASAI } \% \text { ENS }
$$

Not the implementation of TOU

$$
\begin{array}{lllll}
0.92968 & 9.8218 & 10.6673 & 99.8373 & 384306.7
\end{array}
$$

The implementation of TOU

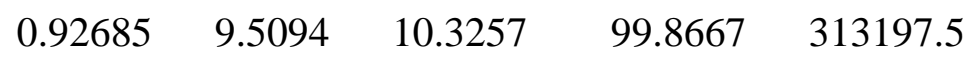

From the results we can see that, after the implementation of TOU, the reliability index is significantly improved.

\section{Conclusion:}

Based on existing research, this article reflects how TOU influences load curve with elasticity and cross-elasticity coefficient. It also uses the method of Curve Clustering to access the reliability of supply with the link of load curve. Eventually it has the summary that demand response improves reliability. Especially using different industry's load curve to reflect the effect of TOU makes the result more real. But I don't consider other incentives of demand response mechanism without existing TOU price policy. Besides, the TOU has diversity so it's hard to get optimal tariff policy exactly. It is necessary to promote model coverage and use the demand response to improve the reliability of supply fully with more optimization.

\section{Reference:}

[1] Wengao Chen. Basis of distribution system reliability. China Electric Power Press, 1998.

[2]Li Shao. Study on distribution network reliability evaluation model and algorithm considering load changes [D ] . Chongqing: Chongqing University, 2007.

[3] Xiangyu Kong, Qun Yang, Yunfei Mu, etc. The analysis method for user load demand response under the environment of TOU [J]. Electric power systems and automation, 2015, 27(10):75-80.

[4] Li Tao, Influence of peak valley electricity price policy on load characteristics [D].Nanjing: Southeast University, 2004.

[5]Hongshan Zhao, Yingying Wang, Song Chen. Influence of demand response on power supply reliability of distribution network[J].Automation of electric power systems, 2015, 39(17):49-55. 